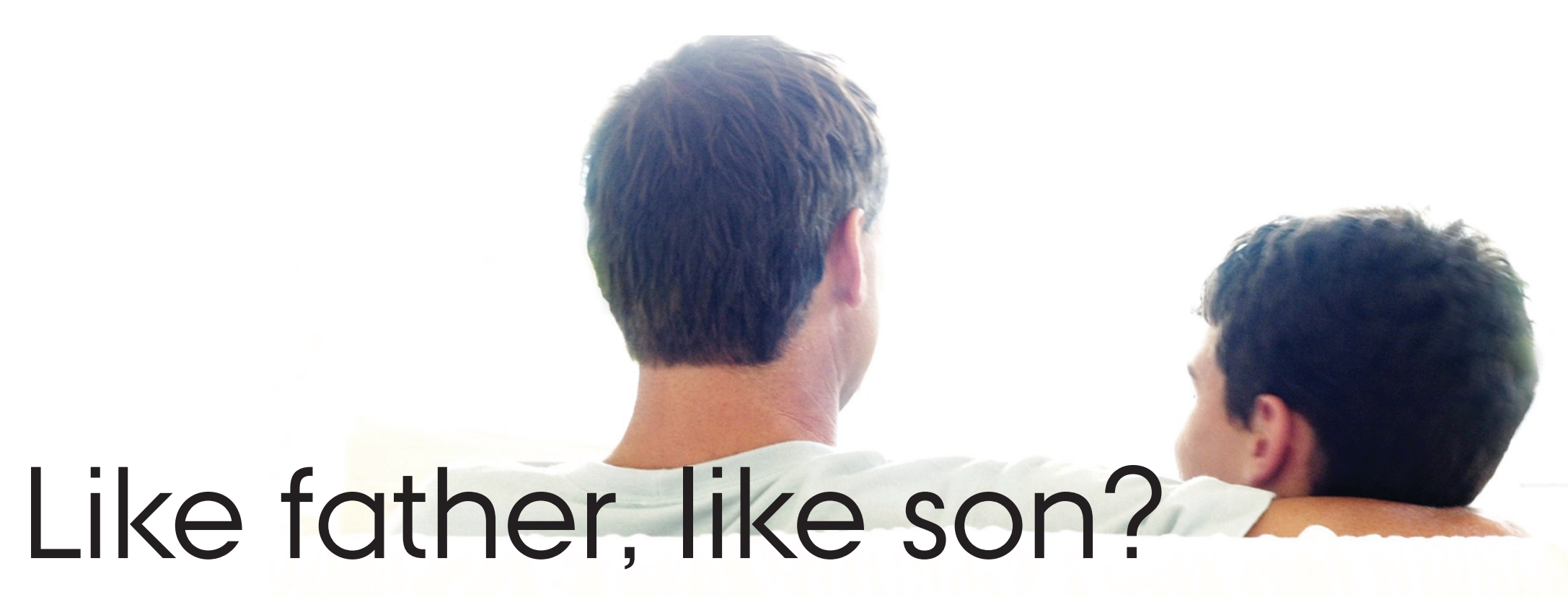

\title{
Intergenerational transmission of values, attitudes, and behaviours in the environmental domain
}

\section{Research question:}

How is young people's pro-environmental orientation related to their parents' pro-environmental values, attitudes, and behaviours? To answer this question, we examine parent-adolescent (aged 16-18) similarities of values, attitudes, and behaviour related to three common household practices: purchasing environmentally friendly products, curtailing electricity use, and handling waste in a sample of 601 Danish families.

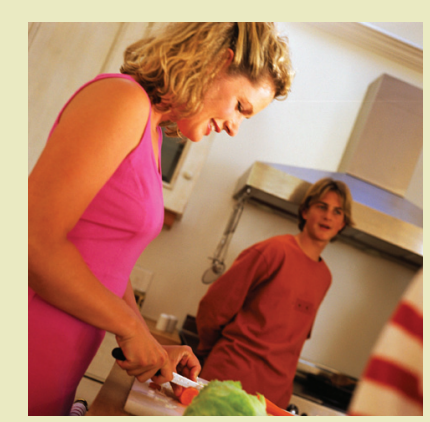

\section{Findings:}

We find that adolescents are less environmentally committed than their parents.

This 'generation gap' appears in measures at all levels of abstraction: from environmental values to attitudes towards the performance of specific pro-environmental behaviours, and to the performance of these behaviours.

Further, we find significant and positive correlations between adolescents' and their parents' pro-environmental commitment at all the analysed levels of abstraction.

\section{Concluding comments:}

Life-stage barriers may be a major reason for the study's findings. Therefore there is not necessarily any reason to expect that the present young generation will retain a lower commitment than older generations in later life stages.

The study suggests that environmental concern and commitment to some extent is transferred from parents to their children. Hence, parents influence the future societal development not only directly through their own acts, but also indirectly through their children.

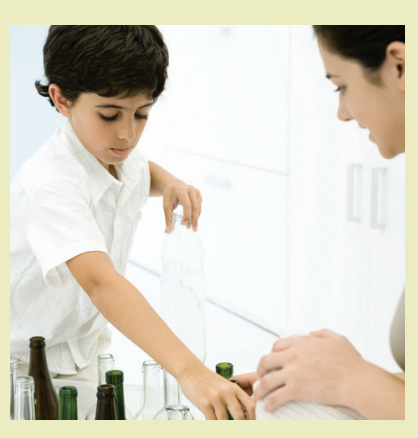

